\title{
CRITÉRIOS PARA AVALIAÇÃO DE BAIRROS SUSTENTÁVEIS: O caso do Bairro Cidade Pedra Branca - SC
}

\author{
CRITERIA FOR THE EVALUATION OF SUSTAINABLE DISTRICTS: The case of Bairro \\ Cidade Pedra Branca - SC
}

CRITERIOS PARA EVALUACIÓN DE BAIRROS SOSTENIBLES: El caso del Bairro Cidade Pedra Branca - SC

Maria Clara Miranda Carcará

Estudante, Centro Universitário Uninovafapi, Brasil. carcara.mclara@gmail.com

\section{Jadiane Beilfuss}

Estudante, Centro Universitário Uninovafapi, Brasil. jadi.beilfuss@outlook.com

Lara Citó Lopes

Professora Mestre, Centro Universitário Uninovafapi, Brasil. Doutoranda em Arquitetura e Urbanismo pela Universidade Presbiteriana Mackenzie- UPM laralopes@uninovafapi.edu.br 




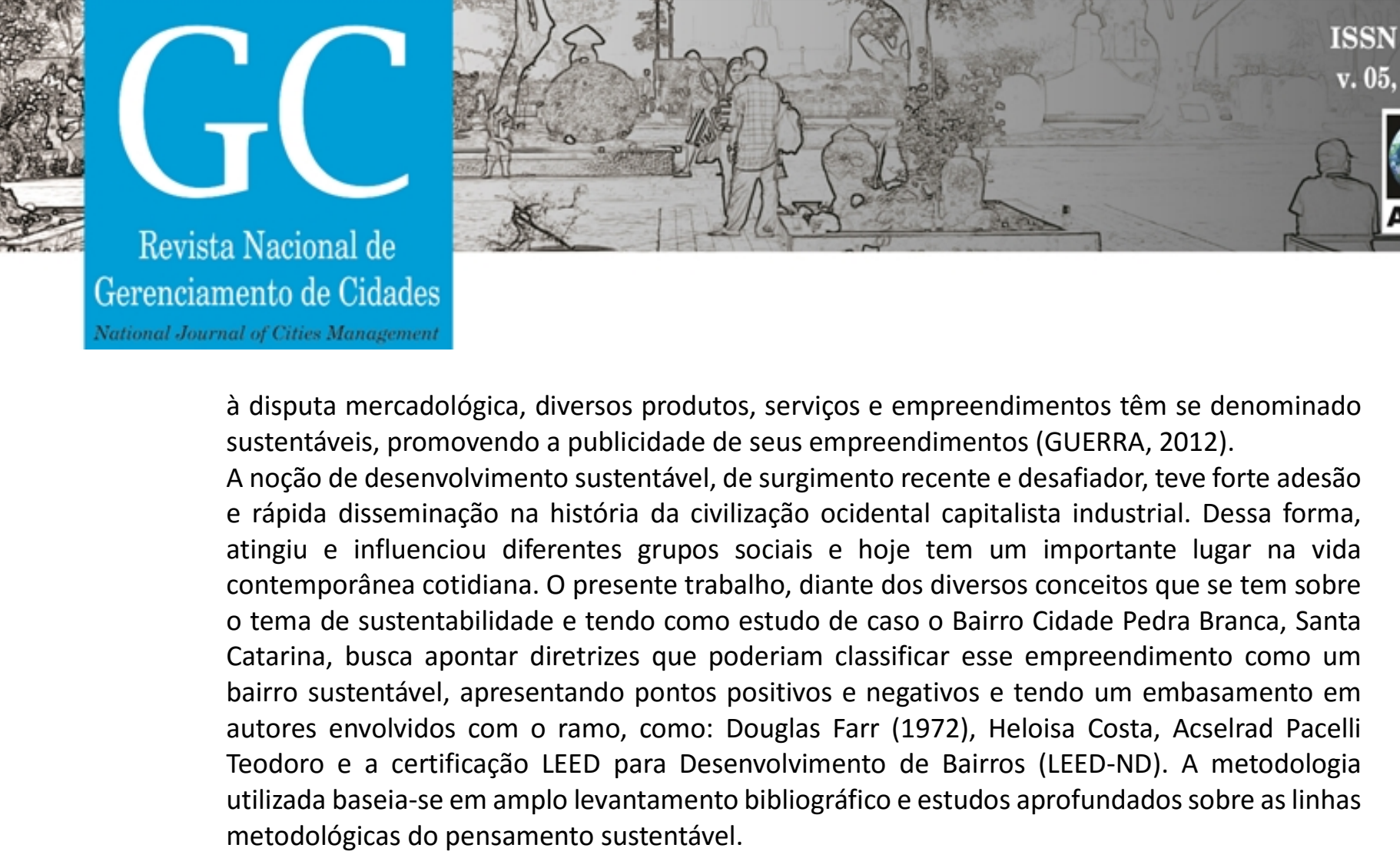

\section{HISTÓRIAS E DISCUSSÕES SOBRE DESENVOLVIMENTO SUSTENTÁVEL}

O desenvolvimento do aparelho urbano está intrinsicamente relacionado com a dualidade cidade e campo já existente desde tempos medievais, quando o urbano dependia do excedente agrícola proveniente do campo para sobreviver enquanto este era responsável pela contabilidade dos recursos e também pela defesa do conjunto (TEODORO, 2013). Esta dependência foi deixando de existir quando as cidades começaram a se multiplicar e aos poucos foram ganhando autonomia em relação ao mundo rural (ABREU, 2004).

Pode-se afirmar que o aumento do contingente urbano, iniciado com o aumento do fluxo de pessoas do campo, proporcionou o cenário industrial que iria trazer diversas mudanças para o contexto das cidades. A partir da chegada das atividades indústrias, que deveria tratar-se de um progresso, acabam sendo causadoras de problemáticas sociais e ambientais, assim, nesse contexto, a natureza passa a ser mais valorizada economicamente. Dessa forma, as primeiras preocupações originadas a partir desses impactos estão intimamente relacionadas ao desenvolvimento urbano sustentável, o qual considera o meio urbano não apenas como usuário do meio rural, mas também como fonte de recursos (TEODORO, 2013).

Em outra vertente geográfica, o termo "sustentabilidade urbana" insere-se na expansão do espaço urbano buscando mudar o padrão produção-consumo da sociedade de forma que o natural deixasse de subjugar-se ao social (TEODORO, 2013). É importante destacar que os impactos ambientais causados pelo aumento populacional também são ampliados conforme os padrões de consumo e produção da sociedade.

Atualmente, a infindável crise urbana enfrentada pela sociedade está relacionada com a permanência de modelos obsoletos e irracionais de ocupação do espaço. A acumulação de capital, má distribuição de recursos e vantagens sociais para poucos tem contribuído para o acirramento de conflitos e contradições (RATTNER, 2009).

Percebe-se, pois, o risco causado pela carência de um planejamento público e privado que determina o crescimento e desenvolvimento das cidades. Mecanismos específicos como a revitalização urbana são imprescindíveis como alternativas para modificações de forma e função arquitetônica nos cenários urbanos, já que concretizam o desenvolvimento urbano sustentável e impedem que localidades precárias de inovações sejam abandonadas e sua população deslocada para outras partes da cidade. 






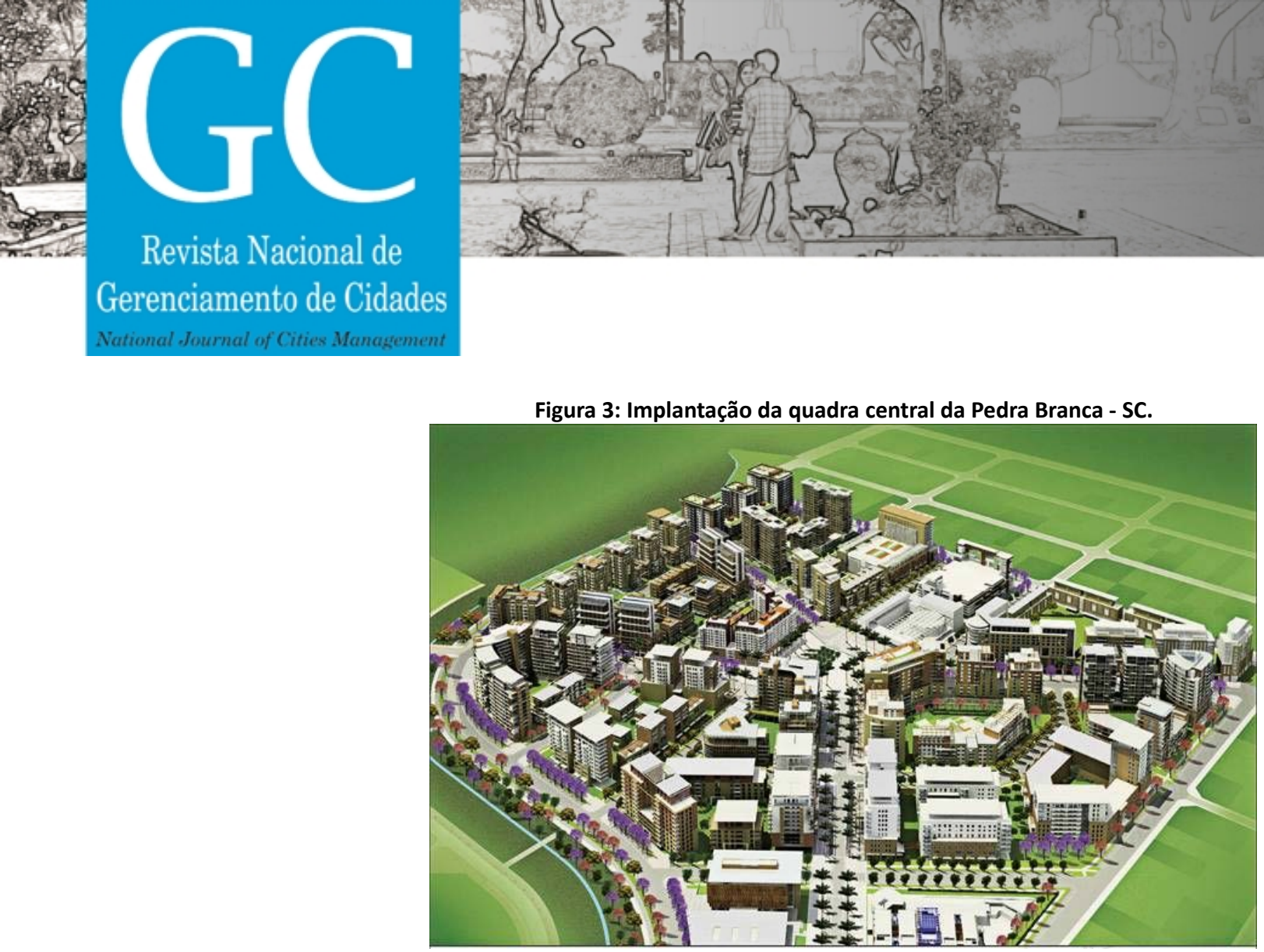

Fonte: Pedra Branca Empreendimentos Imobiliários 2016.

Atualmente são 2.300 lotes, em cerca de 3 milhões de $\mathrm{m}^{2}$. Também incorporaram algumas áreas vizinhas, onde mais de 5.000 pessoas moram, 5.000 pessoas trabalham e 7.000 pessoas que estudam. 0 empreendimento planeja 1,7 milhões de $\mathrm{m} 2$ de área construída e cerca de 12.000 unidades entre apartamentos, escritórios, centros comerciais e áreas industriais leves. A população é estimada em 80.000 pessoas, sendo 50\% morando, 50\% trabalhando e estudando no bairro, em um prazo de pelo menos 15 anos para realização do empreendimento (BAIRRO PEDRA BRANCA, 2011).

O projeto, pioneiro no Brasil e América Latina, segundo Pedra Branca (2011), é reconhecido como novo marco em projetos urbanos para a iniciativa pública e privada. Entre os prêmios recebidos destaca-se o de Urbanismo, da Bienal de Buenos Aires em 2007, do Financial Times de Londres em 2008 e o convite em 2009 pela Fundação Bill Clinton, para integrar o programa de Clima Positivo.

\subsection{Entorno}

A área da fazenda foi considerada um ponto estratégico para a implantação de uma centralidade regional, devido ao planejamento já existente da abertura de alguns eixos de ligação entre os municípios de São José, Palhoça e Biguaçu. Os eixos seriam realizados através da Avenida das Torres, entre São José e Biguaçu, e a Avenida das Universidades, entre São José e Palhoça, que desembocaria diretamente no bairro Pedra Branca. A preocupação com o sistema viário revelava a integração do Pedra Branca com o contexto urbano de Palhoça e, principalmente de Florianópolis.

Estes dois únicos acessos existentes para o Pedra Branca, juntamente com a futura construção da avenida das universidades, formaria os três acessos almejados pela administração. Contudo, esses acessos serão insuficientes para promover a conectividade do empreendimento caso as perspectivas para o transporte coletivo não forem atendidas. Tal infraestrutura torna-se necessária para influenciar na redução do uso de automóveis pelos moradores do bairro, além de integrar o bairro com o restante do espaço urbano. 




Quadro 1: Ações de sustentabilidade aplicadas no Bairro Pedra Branca, Palhoça-SC

\begin{tabular}{|c|c|}
\hline \multicolumn{2}{|r|}{ Ações de sustentabilidade no aspecto enérgetico } \\
\hline Ação & Resultado \\
\hline Planas Fotovoltaicas & Geração de energia limpa \\
\hline Sensores de presença & Menor consumo de energia com áreas comuns \\
\hline Fachadas racionalizadas & Menor ganho de calor e maior ganho de luminosidade \\
\hline Luminotécnica & Lâmpadas com baixo consumo de energia e maior durabilidade \\
\hline Aquecimento solar & Redução do consumo de gás/energia limpa \\
\hline Aquecimento a gás & Melhor eficiência em relação ao uso de energia elétrica \\
\hline Gás natural & Combustível mais limpo e mais barato \\
\hline Medição individual de gás & Racionalização do consumo \\
\hline Motores eficientes & Menor consumo de energia, maior durabilidade \\
\hline Elevadores inteligentes & Redução do número de viagens \\
\hline \multicolumn{2}{|r|}{ Ações de sustentabilidade no aspecto dos recursos hídricos } \\
\hline Ação & $\begin{array}{c}\text { Resultado } \\
\end{array}$ \\
\hline Água da chuva & $\begin{array}{l}\text { Redução do consumo de água potável do sistema potável do sistema público / menor } \\
\text { custo condominial }\end{array}$ \\
\hline Caixa descarga "dual flux" & Redução do consumo de água \\
\hline Torneiras automáticas & Redução do consumo de água e de esgotos a tratar \\
\hline $\begin{array}{l}\text { Torneiras e chuveiros } \\
\text { economizadores }\end{array}$ & Redução do consumo de água potável \\
\hline Válvulas redutoras de pressão & $\begin{array}{l}\text { Redução do consumo de água / maior durabilidade dos acessórios hidráulicos / } \\
\text { menores ruídos nas tubulações }\end{array}$ \\
\hline $\begin{array}{l}\text { Medição individual de água por } \\
\text { telemetria }\end{array}$ & Racionalização do consumo \\
\hline $\begin{array}{l}\text { Paisagismo ecológico com uso de } \\
\text { plantas nativas }\end{array}$ & Menor necessidade de irrigação / maior longevidade de plantas \\
\hline \multicolumn{2}{|c|}{ Ações de sustentabilidade no aspecto conforto ambiental } \\
\hline Ação & Resultado \\
\hline Isolamento acústico entre pisos & Conforto acústico / melhor habitabilidade \\
\hline $\begin{array}{l}\text { Proteção térmica de terraços e } \\
\text { coberturas }\end{array}$ & Conforto térmico / menor necessidade de ar-condicionados \\
\hline Ventilação e iluminação naturais & Conforto térmico visual / redução do consumo de energia \\
\hline Persianas integrais nas janelas & Conforto térmico e acústico \\
\hline Janelas panorâmicas nas salas & Melhor integração interior / exterior \\
\hline Bicicletário & Redução do uso do automóvel / benefícios à saúde \\
\hline Manual de sustentabilidade & Recomendações úteis para melhor utilizar dispositivos empregados no prédio \\
\hline Pomar herbáceo & Paisagismo contemplativo, útil, educativo e promotor da saúde \\
\hline Piscina & Raia para prática de natação esportiva e sem uso de cloro como antibactericida \\
\hline Segurança Integrada & Uso de T.I para tranquilidade dos moradores e redução do custo condominial \\
\hline Acessibilidade & Propiciar segurança e conforto aos portadores de necessidades especiais \\
\hline \multicolumn{2}{|r|}{ Ações de sustentabilidade no aspecto materiais e recursos } \\
\hline Ação & Resultado \\
\hline Cerâmica nas fachadas & Aumento da durabilidade / redução das despesas de manutenção \\
\hline Aço reciclado & Diminuição da poluição ambiental / preservação dos recursos naturais \\
\hline Cimento com cinzas volantes & Diminuição da poluição / preservação dos recursos naturais \\
\hline Ar-condicionado com gás ecológico & Não emite gás de efeito estufa \\
\hline Lixo seletivo & Reciclagem de materiais / diminuição de poluição \\
\hline Coletor de óleo de cozinha & Reciclagem de materiais / diminuição de poluição \\
\hline Coletos de pilhas e baterias & Diminuição de metais pesados \\
\hline Madeira certificada & Preservação das florestas ambientais naturais \\
\hline Alvenaria em blocos cerâmicos & Racionalização da construção / redução da geração de entulhos \\
\hline Estruturas & $\begin{array}{l}\text { Formas metálicas e de polipropileno com redução de entulhos; redução da geração } \\
\text { de entulhos }\end{array}$ \\
\hline Fornecedores & $\begin{array}{l}\text { Preferência por materiais produzidos próximos locais com redução de emissão de } \\
\qquad \mathrm{CO} 2\end{array}$ \\
\hline
\end{tabular}

Fonte: Pedra Branca Empreendimentos Imobiliários S/A, 2014. 




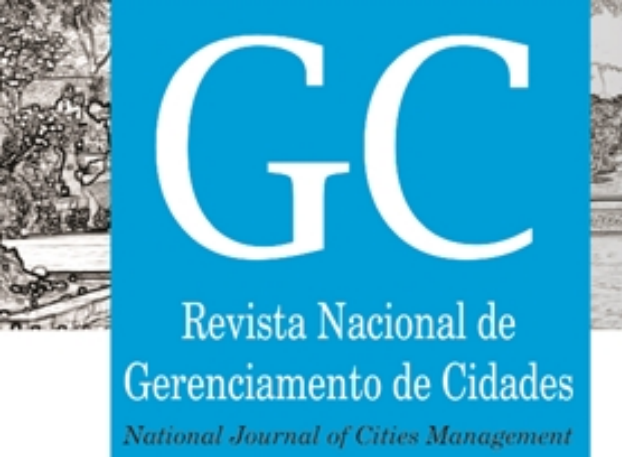

RATTNER, H. Prefácio. In: ACSELRAD, H. A duração das cidades: sustentabilidade e risco nas políticas urbanas. 2ed. Rio de Janeiro: Lamparina, 2009.

RIBEIRO, F. I. Do discurso da diversidade urbana à cidade-mercadoria: um estudo sobre as ideias do New Urbanism e sua transferência para o empreendimento Pedra Branca em Palhoça/SC. 2009. 194 f. Dissertação (Mestrado em Geografia) - Programa de Pós-Graduação em Geografia, Universidade Federal De Santa Catarina, Florianópolis, 2009.

SILVA, M. D.; ÁVILA, G. M. Bairro sustentável: uma alternativa sustentável ou estratégia de marketing?. Cidades Verdes, Rio de Janeiro, v.02, n.02, pp. 43-59, 2014.

SILVA, S.R.M.; SHIMBO, I. Proposição Básica para Princípios de Sustentabilidade. In: ENCONTRO NACIONAL, II e ENCONTRO LATINO AMERICANO SOBRE EDIFICAÇÕES E COMUNIDADES SUSTENTÁVEIS, I, 2001, Canela - RS. Anais... São Paulo: Associação Nacional de Tecnologia do Ambiente Construído, 2001. p.73-79.

STEINBERGER, M. A (re)construção de mitos sobre a (in)sustentabilidade do(no) espaço urbano. Associação Nacional de Pós-Graduação e Pesquisa em Planejamento Urbano e Regional. Número 4. Recife: editora Norma Lacerda: A Associação. p. 09-32, 2001.

TAHCHIEVA, Galina. Entrevista com Galina Tahchieva. Revista de Pesquisa em Arquitetura e Urbanismo, São Carlos: EESC-USP, n. 2, p. 108-110, 2005.

TEODORO, Pacelli. Sustentabilidade e Cidade: A Complexidade na Teoria e Prática. São Paulo. Editora Unesp. 2013

USGBC. Leed 2009 para Desenvolvimento de Vizinhança. Tradução própria. LEED-ND. 2011. Disponível em: <http://gbcbrasil.org.br/leed-neighborhood.php?doc=RaitingSystemNeighborhood. pdf>. Acessado em: 25 out 2016. 